\title{
Runne-Beana: Dog Herds Ethnographer ${ }^{1}$
}

\author{
Myrdene Anderson $^{1 *}$ \\ ${ }^{1}$ Department of Anthropology, Purdue University, West Lafayette, IN, USA. \\ "myanders@purdue.edu
}

\begin{abstract}
Saami society in Lapland (now often called Saapmi), particularly the seasonally-nomadic reindeer-breeding sector, is predicated upon mobility and autonomy of its actors. Runne-Beana, a talented reindeer-herding dog, exhibited both mobility and autonomy when allocating to himself a peripatetic ethnographer, on the first day of five years of doctoral dissertation fieldwork in arctic Norway in 1972. That family's and the wider community's reactions to Runne-Beana's behavior, and mine, highlight the tensions when mobility and autonomy compound with ideologies of ownership and control. At the same time, his companionship profoundly shaped all field relationships, engendering an understanding of dog culture as it is manifest in the herder/herding dog/reindeer triad and in the interpenetration of assumptions concerning child/dog enculturation.
\end{abstract}

Received June 14, 2016

OPEN ӘACCESS

Accepted August 24, 2016

DOI 10.14237/ebl.7.2.2016.725

Keyword Fieldwork reflections, Saami, Reindeer-herding dogs, Reindeer management

Copyright (c) 2016 by the author(s); licensee Society of Ethnobiology. This is an open-access article distributed under the terms of the Creative Commons Attribution-NonCommercial 4.0 International Public License (https://creativecommons.org/licenses/by-nc/4.0), which permits non-commercial use, distribution, and reproduction in any medium, provided the original author and source are credited.

\section{Getting into the Field in Saapmi for Ethnobotany, But Meeting a Dog}

What Every Ethnographer Knows She Doesn't Know

The ethnographer's own identity, entourage (if any), and first contacts inevitably shape the resulting ethnographic project in interesting, unpredictable ways (Agar 1996; Ellen 1987). While I do not recall hearing of ethnographers with non-human companions, I can well imagine that many must have been in such a situation (cf. Wengle 1988:56), and this paper concerns itself with a similar situation. Runne-Beana was a reindeer-herding dog who adopted me when I arrived in the field, facilitating my role as researcher while also enlightening me about Saami culture. In fact, his assistance was crucial to every step (literally) of the first five years of intensive fieldwork and the subsequent now forty years of sporadic but regular annual investigations. Although Runne-Beana died in 1983, he remains a topic in ongoing conversations and online discussions.

Runne Introduces Himself, as Dogs Do

Upon arrival in Lapland (now often called Saapmi) in February 1972 for dissertation research on Saami reindeer management, I zeroed in on a North Norway community of nomads and sedentaries. I had the distinct benefit of sharing virtually no common language with anyone, demanding alertness and imagination on my part. Somehow I let it be known that I was seeking a reindeer-breeding family with whom to live, learn, migrate, work, play, and, hopefully, speak. One woman about my age stood out from the other possible hosts. She intuited that my companionship might combine the instrumental and the expressive: I could be a helpmate, a friend, a scapegoat, a status symbol, and, for the first few months of language-learning, an unhired hand. We both survived, to emerge as life-long friends (cf. Anderson 1978, 1986).

The nuclear family adopting me included two near-adolescent daughters, a younger son, and two dogs. The father-husband had a mature herding dog, Bamse, and the older daughter had a younger dog, then just called Runne. Runne not only had a genuine Saami name shared by most other red or auburn dogs, but his stature and deep coat were along the lines of the original Spitz-Samoyed-Chow-related stock. While gray or spangled-coated dogs will be named Ranne, related to the word for "gray," ranes, no such semantic correspondence obtains for Runne.

Roughly a fortnight after first approaching this potential host family, I returned to their two-room 
frame winter dwelling, somewhat apprehensive that they might have changed their minds or that I had misunderstood. I left my rucksack leaning on an outside wall. The house was filled with many persons, only a few coinciding with the family. My tentative friend welcomed me with interminable cups of coffee.

At some point, still unsure of where or whether I would find shelter that night, or any other night, some youngsters burst into the room with an urgent message. I recognized the cognate loan of "ruck-sack" and the word beana, "dog." One more cognate popped out, rhyming with "piss." Almost incredulous that I decoded the situation, I followed gestures to bring my rucksack indoors. That was when Runne first staked me out as his special companion; it amused everyone else, but I, originally a "cat person," was oblivious of his identity for some time. In the following months, integrated into a larger sii'da herding group of four related families and many times that number of herding dogs, I concentrated on recognizing persons and let the dogs sort themselves out later.

Runne Asserts Himself and Gets a Surname Name, "Dog" On that first spring migration, there was this particularly appealing dog who chose to be either pillow, quilt, or comforter for and to me. The girl who had Runne as her own herding dog, unlike other owners, often fondled him and put him through parlor tricks. He would then look to me rather than to her for rewarding glances. I began to realize how many interesting affective triangles were under brew. Although the dog appeared young and certainly acted that way, even to the extent of abruptly transferring his allegiance to me, I later discovered that he was in his third year.

As Runne attached himself more and more explicitly to me, I started referring to him and addressing him in a fashion habitually used for others of my companion-pets, specifying the species; he became Runne-Beana, 'Runne-dog'. Other persons picked up on this nomenclature-perhaps due to a Saami passion for novelty. It followed that my initial unique and superfluous position gradually transformed into one integral to larger and larger social groups, with this dog as my badge.

Six months later, having accompanied the reindeer and nomad families from the tundra to the coast on spring migration, I needed a separate and fixed field residence for research materials, and in order to be free to meet and travel with as many different sii'da herding groups as possible. I located a cabin-sized dwelling, and moved in with a burgeoning mass of notes, books, tapes, films, plant-presses, hides, and artifacts. At that time, Runne-Beana was "at work" on the range, herding reindeer. The daughter herself rarely spent long periods in herding activities because of school schedules, but would loan her dog to her father so that he could have the benefit of two helpers.

Each time Runne-Beana returned to the settlement, he sought me out and announced himself by howling outside my window. I first assumed the commotion to be friends or neighbors trying to frighten me by sounding like the dreaded wolf. I knew, however, that by the end of the second world war, the local wolf population had been wiped out, even though an occasional wolf might still stray over the Russian or Finnish border only to be killed as a predator. When I would go outside to confront the pranksters, I would only be greeted by Runne-Beana. In complaining about this habit of the dog, neighbors made almost as much noise as the dog.

Realizing that this was not "my" dog, and that he was an indispensable, contributing member to the subsistence activities of his natal and my original host family, I did little to encourage his joining me. At least, I did not feed him. It was impossible, however, not to appreciate his company and the attention we both received, some critical but much of it positive.

A compromise routine developed, whereby Runne-Beana lived with me except when on assignment. The evening before a herding departure, children from the sii'da would be dispatched to locate, relocate, and detain the dog at his proper residence. He would be tied up until taken out to the tundra. Unfortunately, Runne-Beana was adept at escaping any rope, chain, or confinement and would then return to me, where he would be scolded and sent back. Eventually he learned not to show himself to me until his sii'da-mates gave up and left for the herd without him. However, my fieldwork kept me from my headquarters much of the time; if I were not away for hours or days, it could be weeks or months. Whenever Runne-Beana returned to my cabin and could not rouse me by howling, or find me elsewhere by scent, he engaged the help of Bamse, his closest dog-pal, the older dog, owned by the husband-father in his natal family.

While Bamse impressed few with his intelligence, 


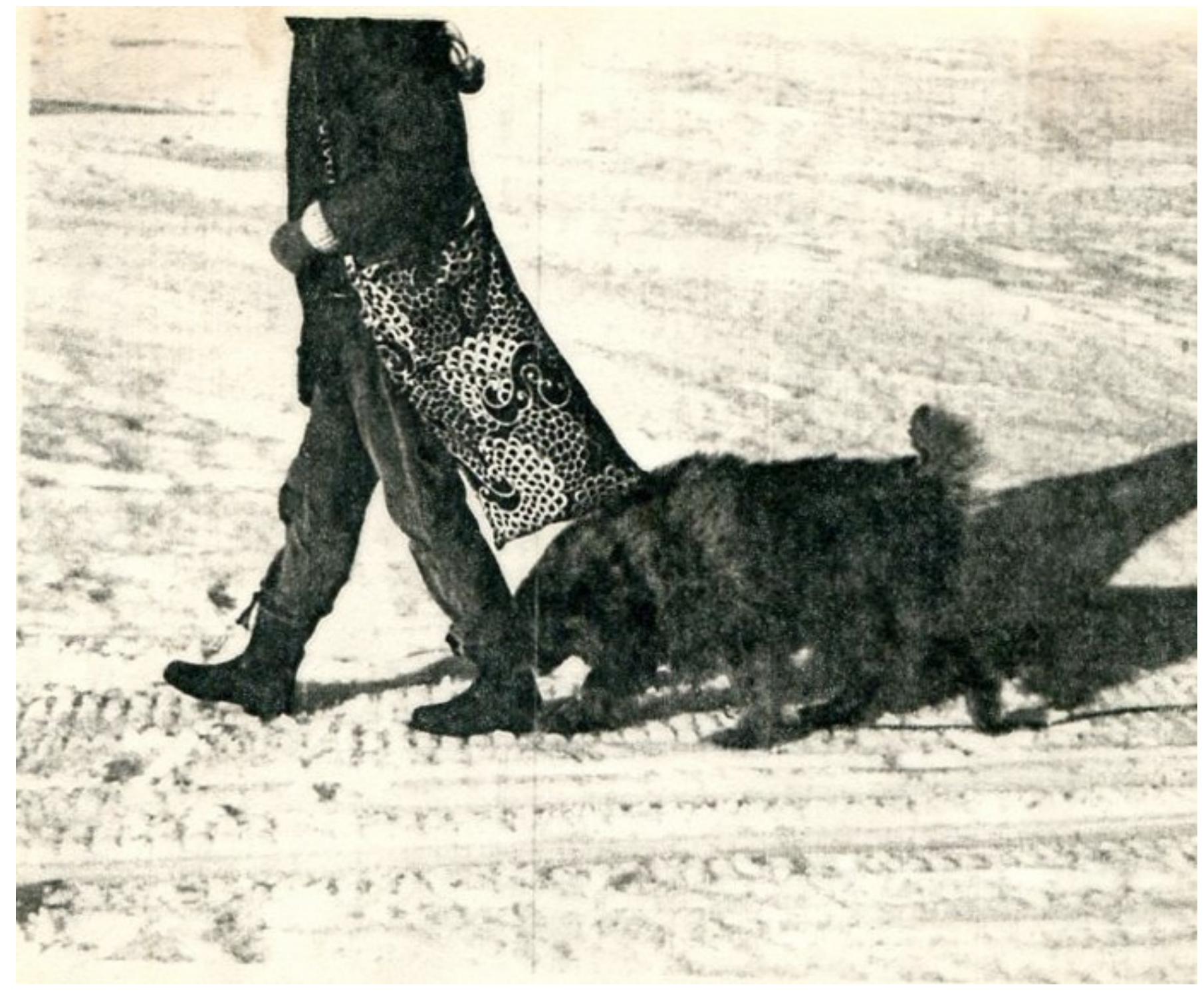

Figure 1 Runne-Beana engaged in ethnography, Kautokeino, Norway, 1979.

he possessed one skill that the younger, brighter Runne-Beana never had to master: Bamse could open doors with a flick of the paw. On occasions when Runne-Beana could not find me at my cabin, he would return to his natal family and fetch Bamse. The two would come to the cabin, and Bamse would open the series of doors to enter the innermost room, my sanctum. There they made themselves comfortable on my bedding and books. Upon my return, I would find doors flapping in the wind, and two (or more, up to a half-dozen) snug dogs inside, all happy to see me.

Runne-Beana, however, preferred not to share my company with these others, and once I appeared, he contrived to drive them off. Often I would be off again on ethnographic errands, accompanied by the jealous Runne-Beana and the lumbering Bamse. On these trips, Runne-Beana took little time in dispatching Bamse on some wild-goose chase so that the two of us could march on alone. Typically, Runne-Beana would seemingly detect a scent worthy of first-order fascination. Bamse took notice of this, but sniff and inhale as he might, only managed to look bewildered. As soon as Bamse was hooked on the belief that there must be a scent to be found if he just tried hard enough, Runne-Beana would dart off in a line oblique to our path, and both dogs would disappear behind a barn guaranteed to be steeped in odors. Evidently, Bamse would be rewarded with scents worthy of 
investigation, and Runne-Beana would trot back to fall into step with me, out of Bamse's line of sight.

Like most Saami dogs, Runne-Beana expected to accompany his consort everywhere (cf. Figure 1), and did not appreciate the Norwegian regulations prohibiting dogs in the local store. While I taught him to understand various commands, including vurde, "wait," he saw no reason not to accompany the very next patron into the store to find me, or he might sneak behind me so closely as not be noticed, by me. In such public settings, persons from his natal family and natal sii'da might recognize Runne-Beana and greet him; he would snub them, feigning nonrecognition.

\section{Runne-Beana Establishes Our Reputation}

All this singular behavior and public exposure led to both Runne-Beana and myself being recognized far beyond our regular circuits, extending over hundreds of kilometers within an area of some 15,000 square kilometers. I became aware that independence, individuality, and innovation were indeed valued in Saami culture. This applied to humans and dogs, and to reindeer and ethnographers as well. Basically, whatever non-deleterious attributes first emerge in the ontogeny of an individual or relationship may be rewarded and utilized as markers. Whether the noteworthy attributes are culturally positive, neutral, or negative, is of lesser consequence-just to be acknowledged as unique in some combination of traits is in itself flattering, contributing to the construction of self. One identifies, and is described, after the more memorable of ancestors in any generation, regardless of sex. The inventory of common names for either gender or humans, and for dogs of any gender, is limited. Parental and grandparental names help disambiguate humans. Dog names usually index color rather than sex, and are disambiguated when necessary by reference to the owner or to the larger sii'da group.

Family groups are seldom physically localized at any time or place. Instead, members - often singly or in ever-changing constellations with each other and outsiders-go about the business of pastoralnomadism, exchanging news and gossip at every turn (cf. Anderson 1978, 1986). One recognizes an approaching figure at a distance largely by the gestalt provided by human-dog combo, each of particular stature, gait, configuration, and color. I too could be recognized by the same method. Even though RunneBeana surely provided little more than redundancy given my assembly of traditional and nontraditional garb, persons always indicated that they recognized Runne-Beana and then deduced that the person must be me.

The summer reindeer pastures in this region lie mostly along the coast in now Norwegian-speaking regions. Runne-Beana and I figured as a pair here as well. The Norwegian friends and trading partners of my original host family, and my own developing network of friends and trading partners, accepted our visits as a relief from their fishing and farming routines. They discussed Runne-Beana's intelligence, traditional build, and independence, and occasionally "dog-sat" while I went off on an errand, even when I returned to the United States almost five years later.

\section{Runne-Beana Goes International Stud}

Runne-Beana was born (probably in 1969) and raised in Norway, about 40 kilometers from the Finnish border to the south. About 100 kilometers farther south, one is in Sweden. The Saami in the far north of all three countries speak the same dialect, intermarry, and even exchange pups, although the borders have been closed to reindeer traffic since 1851. RunneBeana's natal family, and doubtless he himself, had relatives in both Finland and Sweden. This family was also widely respected for its members' personalities, integrity, and herding prowess. Runne-Beana continued to periodically herd with and without me, throughout the first 56-month stint of continuous fieldwork.

Dogs, like children in Saami society, develop skills for which they are known, in a process best described as "ripening" (Anderson 2000). Neither dogs nor children receive explicit training or drills, but become actors as they choose and when they are inspired. Consequently, no two dogs or persons ever share the same complement or quality of skills. Just as humans everywhere learn language without being taught, Saami children, and dogs, also learn skills by casual as well as careful observation, and trial-and-error, or elect to abstain from certain skills, which is always allowed (cf. Anderson 1978; Beach 1981).

In general, an individual dog may be adept at driving a moving herd of reindeer or at monitoring a stationary herd; dogs may also prefer one or another kind of terrain. A herder might keep several dogs with $\mathrm{him} /$ her on the range, because of these differing skills and temperaments, and because to leave dogs at their seasonal dwelling might be inconvenient given the 
interplay of leash laws, bitches in heat, and the like. (On one occasion on the tundra I encountered three herders inside a tent, but first burst out their thirteen dogs.) In work on the range, the herder's commands generally coincided with dog maneuvers, but the combo might instead work at cross purposes, with stern consequences for the dog, even punishment, which would never be the case for children. In leisure, however, the human-dog team was tight-knit, sharing much of the same food and shelter as is available on the tundra.

Runne-Beana preferred driving chores and medium topography; he disliked precipitous, rocky mountaintops and dreaded swimming in icy rivers. I learned he had experienced a few close calls in both environments. Nevertheless, he had a commanding reputation as a herding dog, and as a fighter when need be. He possessed the lines of the pre-contact dog featured in early lithographs. Few such dogs turn up anymore.

I have discussed elsewhere more details about the social and psychological dynamics of canine reproduction, naming, working, and retirement (Anderson 1986). A Saami woman might maintain one breeding bitch. She exercises no selection of stud, for this settles itself suitably among the dogs themselves, to everyone's amusement. In this region, only male dogs are retained as working dogs; female dogs may be equally suitable to herding, but their coming into heat would be disruptive. Therefore, female pups are culled at birth, usually by hanging or drowning - both considered honorable ways of dying. Very senile retired dogs may more likely die by fighting with younger dogs or succumb to accidents on thin ice or perish in bad weather.

About four years into the first fieldwork period, I was visited by two Helsinki women and three bitches in heat. They had been breeding Saami herding dogs for nine years, $1,700 \mathrm{~km}$ away to the south, having an interest in maintaining or even re-constituting the attractive earlier phenotype. The women had contractual arrangements with persons in the Helsinki area who housed bitches and cooperated in their breeding. The only studs to be selected were those recognized as herding dogs in Lapland, so mating entailed long journeys from Helsinki with bitches in tow. The indigenous Saami owner of the stud dog would receive in return at least one male pup, and these would subsequently be monitored for herding aptitude. Other male pups would be sold or distribut- ed in the north, while female pups could either be sold as show dogs to fanciers in the south, or kept as breeding stock if there were reason to suspect they carried auspicious traits for reindeer management. Their genealogical records and reconstructions were the earliest to document Saami herding dogs in this northern region of Saapmi.

Runne-Beana's reputation had reached Helsinki, and his genes were wanted; he cooperated. I was promised a pup that I would give to Runne-Beana's original mistress, but the pregnant bitch was killed by a car in Helsinki. The natal family suspected that I had received payment for Runne-Beana's sexual services, hoping to obtain some token, if only for conversation purposes. There ensued a brief period of animosity. Yet, these new relationships-complicated, involving bitches that had to be smuggled back and forth over the Finnish-Norwegian border-paid dividends for all in terms of our heightened individual and collective profiles, and stories.

\section{Fieldwork With and Without Runne-Beana}

\section{Runne-Beana-The-Linguist}

In a sedentary setting an ethnographer cannot be all places at all times; in a nomadic one, the frustrations multiply by orders of magnitude. However, when Runne-Beana and I were separated, I often later received more detailed information about the events he experienced. With Runne-Beana as a partner, my own social sphere automatically expanded to include his. He confidently accompanied me through packs of aggressive members of his own species and on long treks in unmarked terrain. When lambs and reindeer calves graze on public lands during the summer, regulations prohibit dogs running loose. I observed these regulations to the letter, unlike most Saami, who really could not deploy dogs on leashes in a herding setting.

This brings up Runne-Beana's skill as a language teacher. Living among nomads leaves little opportunity for neat little language drills. One must simply speak, correctly or not. Having chattered to RunneBeana daily, and dreamt in the language at night, I could at least make mistakes smoothly. Saami are pragmatic folk and do not worry about abuses of their language as long as the result is understandable or useful at some level. This absence of negative feedback plus the considerable time devoted to discourse with Runne-Beana, inevitably led to my perpetuating the same errors for years. Similar sociolinguistic dynamics obtain with Norwegian-speakers, at least in 
the north. Their amazement that anyone would learn their language swamps any inclination to provide corrective feedback. Norwegians, though, still judge quirks in a foreigner's speech, while among Saami, idiosyncratic errors can also be chalked up to individuality and innovation, always positively regarded.

Runne-Beana remained alert during any Saami conversation, but appeared to block out any Norwegian one. He also had definite judgments about individuals, without strictly discriminating along linguistic or cultural lines. In the presence of a person he disliked, he would tuck himself out of sight. With members of his natal family, whom he loved, the situation was ambivalent. He could fear their taking him away for work and responded by seeming bashful. Saami devoted considerable time analyzing dog and reindeer behavior in anthropomorphic terms. Through these discussions, I came to appreciate very soon the salient affective states and predominant rationales for behavior.

Runne-Beana-The-Ethnobotanist, or, Stalking the Elusive Beadnag(a)-suoi-dni, "Dog-grass"

Given my interest in all aspects of folk science-and having initially justified this research as ethnobotani$\mathrm{cal}$, focusing on winter-forage lichen as a limiting resource (Anderson 1978)-I looked forward to elucidating the Saami systems of classification, use, and belief with respect to plants and animals. Plants posed a problem, for Saami volunteered little, even about the most crucial of reindeer forage plants. Nor did they consider vegetables particularly edible for humans. Berries were another matter, but only children would sample berries beyond the two species having commercial value (Anderson 2016).

I later concluded that Saami evince less respect for anything sedentary, persons as well as plants (Anderson 1986). They assumed that the reindeer knew enough about botany to forage successfully, so plant identification was not a human concern. I noticed that like other dogs, Runne-Beana would browse on handy monocots that I had no reason to believe would belong to a single species. One of the few plant segregates Saami could/would name and on which all Saami agreed, was beadnag(a)-suoi'dni, "doggrass"; Norwegians also agreed about this, calling it bundegress, "dog-grass"! Usually this identification was assisted by a convenient canine.

Determined to apply myself to at least one research question with hope of resolution, I competed with Runne-Beana to collect some strands of this often mutilated and seldom tasseled grass. Back at Yale's Peabody Museum after five years of collection, comparison revealed that all specimens were of a single species, Dactylis glomerata. In this case, RunneBeana and I had put in a lot of work for only one result. Most of our fieldwork tended in the other directions, with the slightest input generating numerous questions, each leading to a tangle of explanations along with many dead-ends.

\section{Runne-Beana-The-Political-Economist}

Issues of ownership and control rank paramount in Saami society, on par with the emphasis on individuality and independence. Obviously, tension can be expected between ownership, which may be elaborated by all manner of marks, myths, and behaviors, and control, which-despite safeguards and escalating countermeasures when ownership has not been respected-remains virtually impossible to ensure. In Saami culture, all material items, and even social relations and oral chants (Anderson 2015, Beach 1981, Paine 1994), are individually owned—and earmarked or initialed, on the one hand, or forged, hidden, or destroyed by an interloper, as the case may be. RunneBeana belonged to my friend's young daughter, who also became my friend. When the dog opted to adopt himself out to me, there were issues of ownership, of lack of control, and of pride for each of us to confront, and from many angles.

Fortunately, on the matter of face, episodes involving Runne-Beana tended to be tedium-relieving highlights in the community, and members of his natal family could easier maintain their dignity by chuckling along with others than by worrying about personal pride or even legal rights. The acceptance of the dog's independent decision and the dialectic between ownership and control enlightened me as an ethnographer.

Some persons speculated as to whether or not I had purchased the dog, then wondering about the price. One channel of currency into the community was from tourism. Persons were known to sell almost any item for almost any price, and to manufacture both traditional and nontraditional items strictly for this seasonal market. Tourists seeing Runne-Beana were always attracted by his singular character and sociability; I then feared that he could actually be sold.

One reason for this apprehension went beyond my own cultural hang-ups about living with someone else's dog. Retaliation and vengeance are amply 
documented patterns of Saami social behavior (Beach 1981; Paine 1994), as is a diluted version in teasing. Both Runne-Beana and I were teased, for fun as well as viciously. I often had trouble understanding the rationale of the critical camp, comprised of individuals only remotely affiliated with Runne-Beana's natal family. Finally, I noticed that Runne-Beana, his original mistress, and myself were all three considered to be cultural deviants: we exhibited our devotion to each other. Some observers might regard our aberrant behavior as unique and thereby accept it as appropriate in Saami culture where singularity is valued; others with less intimate connection to us, could only be critical, even disgusted, by any overt show of affection, not to mention by my conscientious control of the dog during the seasonal leash period. Yet, whatever the situation, the preferred and default strategy in this society is to take risks. Survivors, including ethnographers, accumulate a lot of adventure stories this way.

Given nonhierarchical, lateral principles underlying Saami social organization (Beach 1981; Pehrson 1957), social and antisocial acts often escalate with waves of exacerbating positive feedback. Hence, reindeer theft, rustling, and poaching have been known to develop between two persons, relatives or not, or between two sii'da groups, to the extent that one party might even wipe out the holdings of the other (Anderson 1978). Contemporary versions of such escalating antagonistic behavior include the occasional unplugging of food freezers. But these are culturally marked actions, dampened by more general social disapproval and, potentially, recovered by rapid returns in reindeer management.

Consequently, the relationship between RunneBeana and myself could easily have been a casualty of any number of cultural forces. The most serious to manifest involved some older children of several sedentary families. These children had been raised with the customary freedom and absence of social restraint characterizing their unique "ripening," but in the case of non-nomads without the usual insurance provided by environmental push-back. Until recently, Saami children were basically raised first by nature itself, thence by a virtual village (Anderson 1978, 2000). Moreover, in a rapidly changing milieu, opportunities for mischief, theft, and vandalism steadily increased for sedentary children, who, unlike nomad children, had fewer competing healthy pastimes.
Nomads and sedentaries are interdependent, particularly between the Saami nomads of the interior and the Norwegian sedentaries at the coast near the reindeer's summer pastures. However, between the nomads and Saami sedentaries of the interior winter village, the relationship can be more antagonistic, with the sedentary voicing envy at the more free, traditional lifestyle of the nomad who often has more "real" as well as conventional wealth, partially given subsidies afforded reindeer management. Because both RunneBeana and I associated more with nomads, we were at risk for this type of resentment from sedentaries, the local majority.

The sedentary children in question threatened to mistreat Runne-Beana, and on occasion were able to carry out violence with rocks, air-guns, and speeding vehicles. This was the main reason I could not simply transfer the dog back to his natal family when I left the field at the end of 1976, for Runne-Beana would predictably look for me at my last cabin, in a hamlet near these locally-labeled delinquents. After one of the more acrimonious altercations, the children made a threat that sent me reeling; I was forced to recall some of the older collections of folklore I had skimmed in foreign libraries many years before. Runne-Beana was promised the most excruciating death imaginable, that reserved for the despised wolf in former times - to be skinned alive and turned loose. I cannot finish that sentence.

\section{On Closures: Runne-Beana in Retirement and Beyond}

The Dissertation - "Closure" Short of Death of Any Party

During my final year in the field, I made every attempt to remain sedentary to work on the dissertation, a situation that was hard on both the dog and myself. At spring migration time, Runne-Beana was needed on the range, but I foresaw no way to apply myself to writing without his companionship. Runne-Beana stayed home with me, missing the opportunity to become a film star in Marlin Perkins" "Wild Kingdom" documentary.

As the time drew ever nearer for my first departure from the field, in the fifth year toward the end of 1976, I was at a loss as to resolving the proper placement of Runne-Beana, my closest friend and major consultant. For various reasons, I felt that continued full-time work with his natal family's reindeer herd would decrease his lifespan and not necessarily contribute to his happiness. Alternatively, 


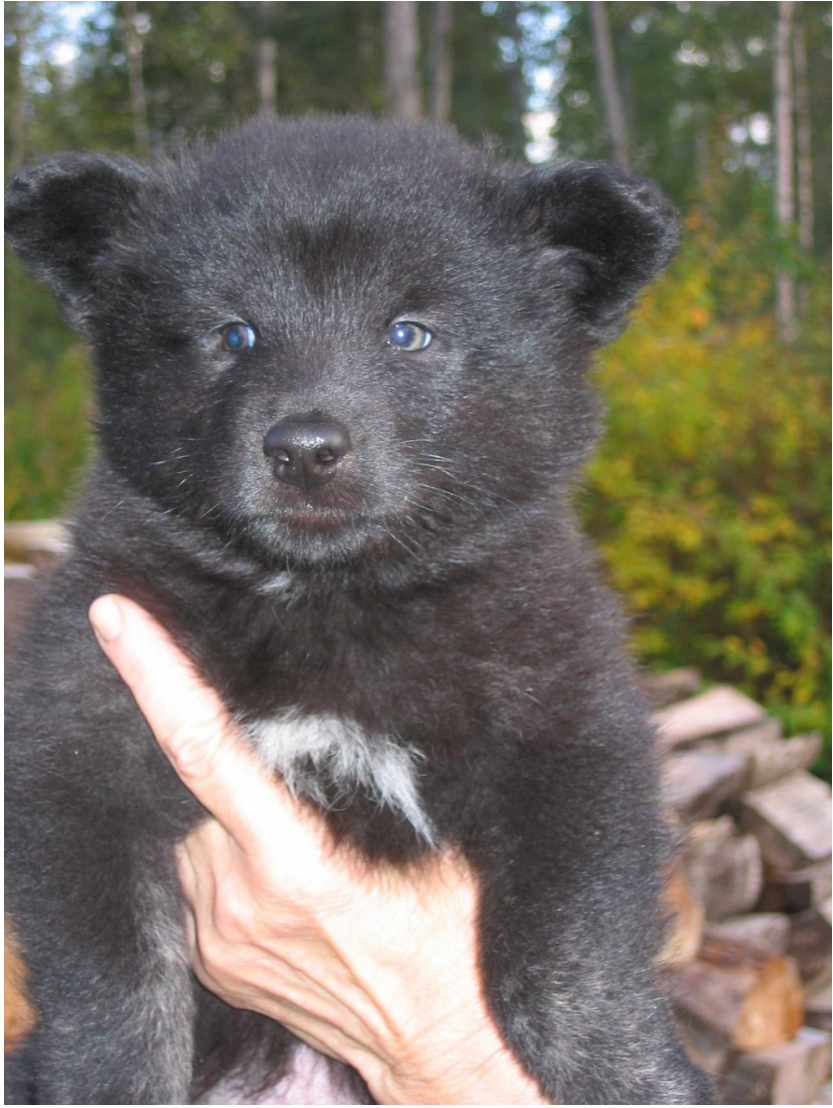

Figure 2 Muste-Beana in Finland at 6 weeks, before emigration to U.S.A. at 10 weeks.

for the dog to join me in the United States could have the same result; worse yet, once out of Norway, he could not return without undergoing a strenuous quarantine period. Fortunately, at the time of packing the final crates, none other than Runne-Beana's stud connections unexpectedly showed up from Helsinki. These two women had a new proposition. They wanted to borrow Runne-Beana for a few months of stud service in the south. Without fully realizing what was happening, I agreed, solving in many ways my immediate problem of his disposition.

When Runne-Beana returned to the north from Helsinki some five months later, shampooed and brushed, his natal mistress's mother entered him in and won a ribbon at the first and perhaps only Saami reindeer-herding dog show in the north, in the spring of 1977. Photographs attest to his fine condition, but by the next following summer, after a year on the tundra under harsh working conditions, his age was showing. By this time, the dissertation out of the way, I intervened-behaving unilaterally and consequently in the best Saami manner. I arranged for RunneBeana's retirement with a coastal farm family where he was guaranteed fish every day and plenty of attention from familiar folk. Accusations of kidnapping only added to my reputation. This was, after all, how I had acquired the dog in the first place.

The dissertation (Anderson 1978)-neither ethnobotanical nor ethnozoological, but, following Hal Conklin's not-so-secret passion, ethnoecological-had been dedicated to Runne-Beana and the various creatures assisting me along the way. Each time I returned to the field, regularly each summer and for fourteen months during 1979-1980, I would borrow my retired companion and best collaborator for the duration. We would visit, trek, camp, and share in all the treats and hardships of field research. During an absence, around Easter of 1983, Runne-Beana died in his fourteenth year, an unusually old age for these conditions. He was buried in a special place that I found difficult to visit, even though, annually, I am right there. Between Runne-Beana's demise in 1983, and the Chernobyl disaster of 1986, there were years when it was very stressful to carry on with fieldwork, though I did and still do.

\section{Muste-Beana-Runne-Beana's Gift to America}

One of the two Finnish friends once involved, decades before, with Saami reindeer herding-dog breeding, contacted me early in June of 2004 with news. She was adopting a pregnant bitch, Tulikki, who was a descendent of Runne-Beana, one of her favorite studs back in the day. Tulikki's genealogy showed five links back to my old dog, and the father dog had three. My friend assured me that she would save me the best of the litter.

I already knew that come fall, following my usual summer fieldwork in Lapland, I would attend an international interdisciplinary conference on Culture, Nature, Semiotics, in Tallinn and Tartu, Estonia-an overnight ferry from Helsinki, and thence a short train ride to my Finnish friend, and Tulikki's pups. I cleared my calendar for all contingencies, at least the ones I might anticipate.

By email attachment, following the birth of nine pups on July 31, 2004, I followed the squirming brood, seemingly mostly black, whereas my old Runne -Beana had a distinctive auburn coat. Then to celebrate their attaining six weeks of age, my friend sent me individual but unlabeled portraits. I had no idea as to which was "best of the litter," although I had been told that it was a little spangled female. 
I froze, fixating on a single portrait that resembled a baby bear. However, the image did not look "like a girl," and was quite black, not spangled (Figure 2). This was the state of affairs as I arrived in Estonia. On the ferry to Finland, I resigned myself to the fact that I had fallen in love with the wrong portrait. Since I felt committed to adopt the reserved female, the only solution would be to adopt two dogs. With trepidation, I arrived in Finland to meet "the best of the litter, my puppy," and her siblings, including the tall, black, handsome Muste-Beana. All black dogs are named "Muste," in Saami, by the way, but unlike "Runne," there is an etymological connection with Finno-Uralic words for "black" and even "ink," although not in Saami itself.

Little did it occur to me that Muste-Beana might have already been purchased, as indeed five other pups had been. But there he was, with two brothers and the best-of-litter sister. The four pups were given two elk knuckle bones, and I proudly witnessed Muste -Beana take ownership of the larger of the huge bones, drag it near a doghouse where there were some ready-dug holes, then position it in one, which was not nearly deep enough. I was thinking, oh, that's what dogs do, they bury bones; however, he used the shallow hole as a fulcrum to aid his front paws in rotating the bone to best advantage. Being a cat person, I was impressed.

Fast forward to 2016, Muste-Beana, and his sister, became 12 years old. His sister had been immediately adopted by a long-former student's daughter when we arrived from Finland, but this year she moved to upstate New York. However, Muste-Beana has a new friend. In spring 2016, coincidently from upstate New York, we adopted a blind colleague's 13-year-old retired service dog, herself with vision issues. Now Muste-Beana has someone larger than cats to herd. However, each December, he does pose with illuminated strings of harnessed reindeer that show up in neighborhood yards.

\section{Notes}

${ }^{1}$ This paper, exclusive the current closure, was presented at the symposium I organized for the $60^{\text {th }}$ annual meeting of the Central States Anthropological Society: "Human-alloanimal Social Relations, (I), Work and Play, Doggedly"; Lincoln, Nebraska, 26-28 April 1984.

\section{Declarations}

Permissions: None declared.

Sources of Funding: None declared.

Conflicts of Interest: None declared.

\section{References Cited}

Agar, M. 1996. The Professional Stranger: An Informal Introduction to Ethnography, $2^{\text {nd }}$ edition. Academic Press, San Diego, CA.

Anderson, M. 1978. Saami Ethnoecology: Resource Management in Norwegian Lapland. Unpublished Doctoral Dissertation, Department of Anthropology, Yale University, New Haven, CT.

Anderson, M. 1986. From Predator to Pet: Social Relationships of the Saami Reindeer-Herding Dog. Central Issues in Anthropology 6:3-11.

Anderson, M. 2000. Saami Children and Traditional Knowledge. In Ecological Knowledge in the North: Studies in Ethnobiology, edited by I. Svanberg and H. Tunon, pp. 55-65. Swedish Biodiversity Centre, Uppsala, Sweden.

Anderson, M. 2015. Musing on Nomadism: Being and Becoming at Home on the Reindeer Range. In Stories of Home: Place, Identity, Exile, edited by D. Chawla and S. Holman Jones, pp. 17-30. Lexington Books, New York, NY.

Anderson, M. 2016. Food Trends through Two Generations amongst Saami in Arctic Fennoscandia. In Gender and Food: From Production to Consumption and After, Advances in Gender Research 22, edited by V. Demos and M. Texler Segal, pp. 3-23. Emerald, New York, NY.

Beach, H. 1981. Reindeer Herd Management in Transition: The Case of Tuorpon Saameby in Northern Sweden. Uppsala University Press, Uppsala, Sweden.

Ellen, R. F. 1987. Ethnographic Research: A Guide to General Conduct, $2^{\text {nd }}$ edition. Academic Press, New York, NY.

Paine, R. 1994. Herds of the Tundra: A Portrait of Saami Reindeer Pastoralism. Smithsonian Institution Press, Washington, DC.

Pehrson, R. N. 1957. The Bilateral Network of Social Relations in Konkama Lapp District. International Journal of American Linguistics (II) 23.1.

Wengle, J. L. 1988. Ethnographers in the Field: The Psychology of Research. University of Alabama Press, Tuscaloosa, AL. 